\title{
Model and Fabrication of CNC Plotter Machine
}

\author{
Udit Pandey $^{1}$, Swapnil Raj Sharma ${ }^{2}$ \\ Department of Mechanical Engineering, BBD Engineering College, India ${ }^{1,2}$
}

\begin{abstract}
Today the Growth of Technology and utilization of CNC machine are Rapid increased. The idea Behind Our Project is to Design a CNC plotter machine with using Arduino and CNC shield, it is capable to design machine mechanical parts and $2 \mathrm{~d}$ design. This is fabrication of low cost CNC Machine and decreased cost and complexity. This Paper is help to design and fabrication of mini CNC Plotter Machine. In this machine only G codes are used to command or instructions. G codes are language, by using this person Told computer control machine tool. The CNC machine is design $3 \mathrm{~d}$ objects in $2 \mathrm{~d}$ paper. We have also used CNC Plotter Machine for $3 \mathrm{~d}$ Printing.
\end{abstract}

Keywords: CNC Shield, SMPS, Arduino Board, Arduino Drivers, G Codes

\section{INTRODUCTION}

Mini CNC plotter machine is described as it is based on Arduino controller and CNC shield. CNC is computer numerical control machine. G codes are preparatory Function. G codes are pre-define Function Associated with the movement on machine axes. In CNC Plotter Machine only G codes are used. G codes are giving the Direction to move the pen in X, Y, Z directions. Pen can be changed by tools of drilling, laser cutting tool, milling it can be worked, if it is made in large size. The aim of over is to make a mini CNC plotter machine which is capable to draw difficult design in paper or surface of metal, To cut it with a great accuracy.We have used 3 stepper motors with lead screw in Cartesion coordinate X, Y, Z directions. Stepper motor is convert digital pulse into lead screw rotations. Stepper drivers are used to give command to the system. The main aim is to fabricate a MINI CNC plotter Machine to draw an object with using $\mathrm{G}$ codes. We also work on to reduced cost of the project and increase Reliability and Flexibility. In we have replace pen with mechanical tools drilling, grinding, machining etc. This will be used for soft material cutting or machining, laser cutting machine tool is also worked on this setup. We have reduced the cost, in the setup of mini CNC plotter machine.

\section{METHODOLOGY}

We have supply the current in Arduino with USB DATA cable to transfer Data from Computer to Arduino Board [1], Here we have used 3 Stepper Drivers to supply the G codes in Sequence to the stepper motors. Arduino will be mounted on CNC shield. CNC shield will be distribute the Current in the command of Arduino. CNC shield will be convert the command of $\mathrm{G}$ codes in digital pulse by Stepper motor. In X direction Stepper motor will be move left and Right , Y direction stepper motor will be move in front and back direction, $\mathrm{Z}$ direction Stepper motor will be move in Up and down[2]. We have make many difficult design via using this machine. The accuracy of this machines results is very high. So we have used in industry to reduce the cost of design printing and maintain accuracy level. Drafting and Scaling of CNC Plotter machine is very precious.

\section{BLOCK DIAGRAM}

Mini CNC Plotter Machine is worked on input as a G codes of Design and Converting it via use of Arduino, Stepper Drivers, CNC Shield, Stepper Motor in to a Rotation of Lead screw. We have work on to maintain lowest cost of our project. We have design a simple construction of our project. This is easier way to use stepper motor with lead screw, CNC shield, Stepper drivers, Arduino Board, etc. The Setup of machine is flexible that's why it will be easily transported and Maintenance time is short. The basic diagram of CNC Plotter machine is shown in figure.
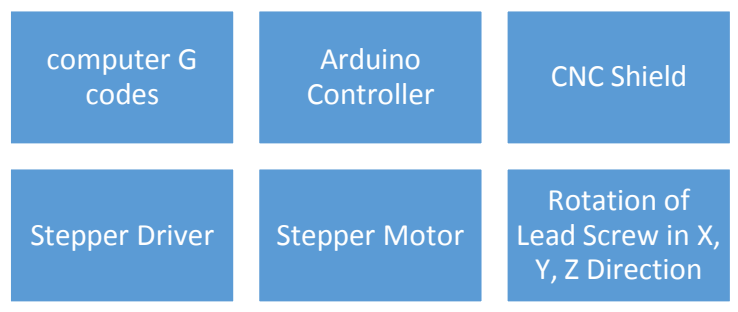

Rotation of

Lead Screw in $X$

Y, Z Direction

Fig. block diagram mini CNC plotter machine 


\section{PREPARATORY FUNCTION}

This is presented by "G". G codes are pre-define Function associated with the Movement of Machine Axis [2]. It has Two Digits, Ex- G00, G81, and G90. It is possible to include more than one G address in one block. Provided these Functions are not mutually Exclusive [3]. Ex- G02 and G03 are together in one block are not Permissible. G function are define the path to be followed a complete design. Ex-

G00- positioning

G01- Linear interpolation

G02- Clockwise Circular Interpolation

G03- Counter clockwise Circular Interpolation

G04- Dwell

\section{ARDUINO UNO}

Arduino will be define as, it is received the command or data from the computer and with the help of USB cable. It is mounted on $\mathrm{CNC}$ shield, it will be transfer data from Arduino to $\mathrm{CNC}$ shield with using stepper driver. Arduino UNO is a microcontroller board, it contains everything needed to support the microcontroller, simply connect it to a computer with a USB cable and a power source. It controls the position of stepper motor with help of a program [2]. It is open source platform based on easy to use hardware and software. T have digital and analog input/output pins which can interface into various expansion board and other circuits and microcontroller with complementary components that helps in programming and incorporation into other circuits[3]. Current supplied 5 volts with USB cable.

\section{CNC SHIELD}

The Arduino CNC shield make it to easy that CNC project up and running in few hours. It is use open source firmware to control three stepper motors using three piece of stepper driver; s breakout board, with this shield and Arduino [1]. We can built a mini CNC plotter machine which is easy to control and flexible working. Current supplied to CNC shield is 12 volt by using SMPS (switched mode power supply). CNC shield is Control the Current distribution on each motor. Stepper Motor will be run on in this criteria of bed size which is $50 \times 50 \mathrm{~mm}$. If we have increase the size or length of lead screw we will make big design by using this machine. CNC shield will be supplying the power on the all three Stepper motors. CNC Machine will be work on the shortest distance of path on Designing of object.

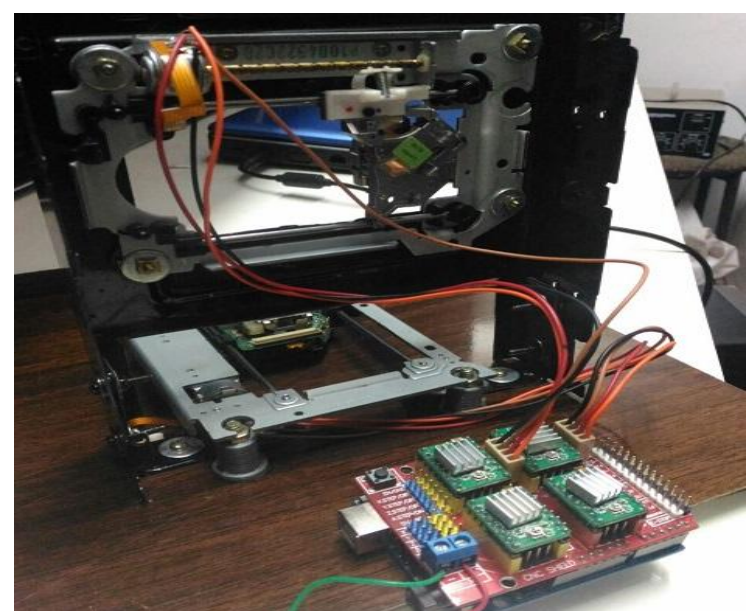

Fig. Arduino and $\mathrm{CNC}$ shield mounted

VII. STEPPER MOTOR

Stepper can be converted digital pulse in to a movement of pen with respect to axis $\mathrm{X}, \mathrm{Y}, \mathrm{Z}$ direction. A stepper motor is a brushless motor that divides a full rotation into a number of equal steps, the stepper motor is known by its property to convert a number of impulses into a defined increment in the shaft position. Each pulses move the shaft through a fixed angle. We have used 3 stepper motors with lead screw. Motor output will be in the form of rotation of lead screw with respect to $\mathrm{X}, \mathrm{Y}, \mathrm{Z}$ Axis. Input current supplied is 12 volts through SMPS. 

ISO 3297:2007 Certified

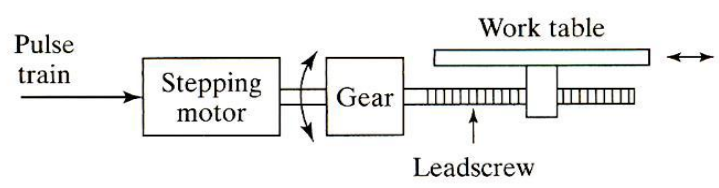

Fig. stepper motor

\section{STEPPER DRIVERS}

We have used three stepper divers which controls the movement of stepper motors along the $\mathrm{X}, \mathrm{Y}$ and $\mathrm{Z}$ axis. Stepper driver are mounted on Arduino [2] .We have supplied input current of 5 volt through USB cable. Stepper drivers are mounted on CNC shield, it will be control the supply of Stepper motor current. Motor will be gives result as a rotation of lead screw. Lead screw will be control the movement of pen.

\section{HARDWARE DECRIPTION}

We have used stepper motor of DVD writer of computer, hardboard, CNC, shield, Arduino board stepper drivers, led. We have designed base parts through auto cad and manufactured it by $3 \mathrm{~d}$ printing Machine.First convert any picture in inscape software than it will be converted into it dxf file. This dxf file will be converted through cambam and generate into a $\mathrm{G}$ codes. Universal $\mathrm{G}$ code runner will be compiles the $\mathrm{G}$ codes.

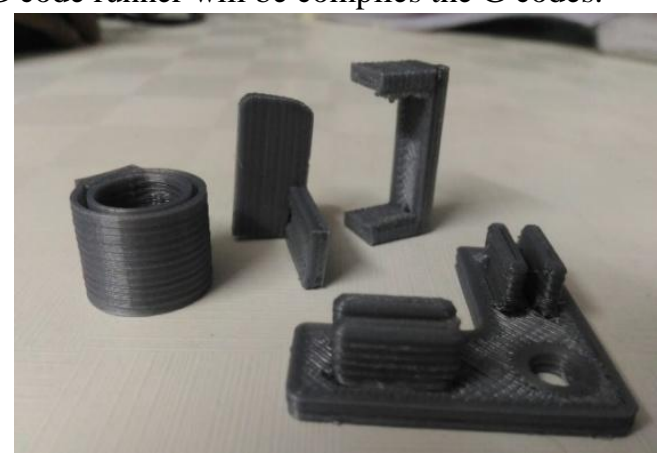

Example- Spur gear G codes

Some base hardware plastic parts are designed and manufactured. The whole setup is mounted on it.

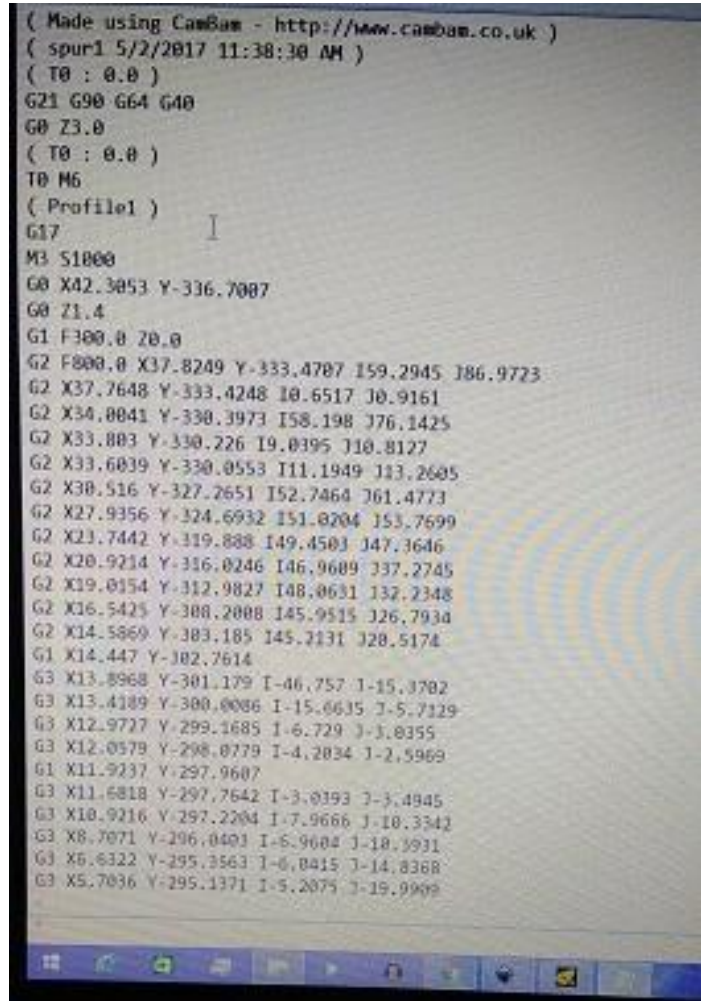

Fig. spur gear $\mathrm{G}$ codes page 1 


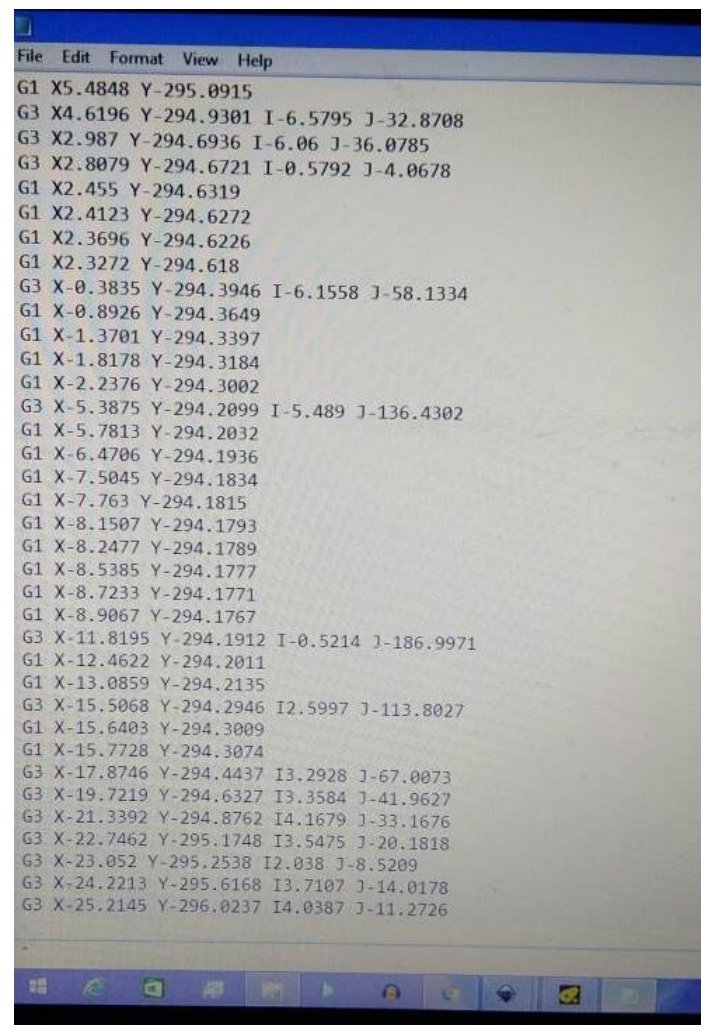

Fig. Spur gear $\mathrm{G}$ codes page 2

This is coding of Spur Gear in the Form of G codes that is working to make a design in 2D paper. This Codes are run on Universal G Code Runner Software. Universal G code Runner will be Run G codes one by one in line. In Future we have used tools of machining in the replacement of pen. This machine will work on cutting of tool using Laser Beam in soft materials.

\section{CONCLUSION}

In this paper we have used concept of low cost mini CNC plotter machine, which is easily control with computer and suddenly stop and paused by click action on computer. By using this we have make Difficult and Complex Design in paper. This is small machine which is easily Transportable and Assembled everywhere on Requirement of it. Bed Size of this machine is $50 \mathrm{X} 50 \mathrm{~mm}$. Stepper Motor will be run on in this criteria of bed size. If we have increase the size or length of lead screw, it will be free to make big size of design in paper. We have used $\mathrm{G}$ codes to giving command [1]. G-codes are language to give the command to the machine to move right, left or up and down. On the successful work of this machine we have some change on it and make it commercial used and applying tools for cutting, grinding of soft material etc.

\section{REFERENCES}

[1] Kajal J. Madekar', Kranti R.Nanaware ${ }^{2}$, Pooja R. Phadtare ${ }^{3}$,Vikash S. Mane, "Automatic mini CNC machine for PCB drawing and drilling" International Research Journal of Engineering and Technology (IRJET), Volume: 03; Issue: 02; Page No. 1106-1110; 2016

[2] N. Balasubramanyam and Prof. Smt. G. Prasanthi "Design and Fabrication of an Automatioc PC- Based Drilling Machine", HCTL Open International journal of Technology Innovation and Research, Volume: 07, 2014

[3] K. Nagai, "Learning while doing: Practical robotics education" IEEE Robotics \& Automation Magazine, Volume: 08, Page No. 38-43, June 2001

[4] Shrikant Bhange, Lochana Ahire, Madhuri Gadkari, Ashmita Bhosale, Mansi Shrimali PC CONTROLLED PCB DRILLING MACHINE" International Journal of Engineering Technology and Computer Research (IJETCR), Volume-3, Issue-1; Page No. 64-66

[5] D.S. Bernstein, "Setting up and running a control Research Laboratory" IEEE Control Systems Magazine, Volume-23, Page No-14-19, 2003

[6] K. Nagai, "Learning While Doing: Practical Robotics Education", IEEE Robotics \& Automation Magazine, Volume-8, Page No-38-43, 2001

[7] V.K. Pabolu and K.N.H. Srinivas, " Design and implementation of a three dimensional CNC Machine”, International Journal Computer Science and Engineering, Volume-2, Page No-2567-2570, 2010

[8] I. Pahole, L. Rataj, M. Fisco, S,Klancnik, S. Brezovnik, M. Brezocnik, and J. Balic, “ Construction and Evaluation of Low-Cost Table CNC Milling Machin," Scientific Bulletin, Series C: Mechanics, Tribology, Machine Manufacturing technology, Volume-23. Page No- 1-7, 2009

[9] T. Andrei and I. Nae, "Designing and Bulding CNC Router Using Stepper Motors", Seria Technical, Volume-12, Page No- 55-62, 2010

[10] T. Andrei and I. Nae, "Practical Applications Performed by a Stepper Motor CNC Router" Seria Technical, Volume-12 Page No- 127-138, 2010

[11] X. Xu, Y. Li, J. Sun and S. Wang, "Research and development of open CNC System Based on PC and Motion Controller", Procedia Engineering, Volume- 29, Page No- 1845-1850, 2012 